\title{
A METHOD FOR ANALYZING THE EFFECT OF IMPLEMENTING AN ENTERPRISE SYSTEM BASED ON THE COMPLEXITY OF ACTIVITIES
}

\author{
Chijoo LEE ${ }^{*}$, Chiheyon LEE ${ }^{2}$, Eul-Bum LEE ${ }^{3}$ \\ ${ }^{1}$ Department of Architectural Engineering, Yonsei University, Seoul, South Korea \\ ${ }^{2}$ ALUX Company Limited, Seoul, South Korea \\ ${ }^{3}$ Graduate Institute of Ferrous Technology \& Graduate School of Engineering Mastership, \\ Pohang University of Science and Technology, Pohang, South Korea
}

Received 12 April 2018; accepted 14 August 2018

\begin{abstract}
This paper presents a method for analyzing the effect of implementing an enterprise system (ES) in the construction industry during the ES introduction and planning stages. The effect is a reduction in employees' work time. The proposed method is based on the 1) level of digitalized and automated activities, the 2) complexity of the activities, and the 3) complexity of the processes in the workflow. The method was applied at a construction company that has no enterprise resource planning (ERP), and the method's accuracy was evaluated by information technology consultants who have performed planning, construction, and operation in relation to ERP. The result shows that the effect of management business was the largest; most of this effect was on data management and review. After users became familiar with ERP, the reduction in data input time increased. The analysis method takes less time and costs less than using surveys to measure the work time and satisfaction of ES users. It can also identify processes in which the effect increases or decreases, thereby guiding any modifications of the ES before it is introduced.
\end{abstract}

Keywords: working time, workflow, activity, process, automation and digitalization.

\section{Introduction}

The rate at which companies in South Korea have invested in information technology (IT) has been increasing steadily (National IT Industry Promotion Agency 2008-2016). Many previous studies proposed success factors and strategies to ensure efficiency when investing in enterprise system (ES) implementation (Mamoghli et al. 2015; Ngai et al. 2008), but few previous studies proposed a method to analyze the effect of IT implementation. ES is the type of customized IT system for requirements and unique processes of company (Lee, C., Lee, C. 2017). Rather, previous studies proposed a method to analyze the effect after ES was implemented, but not before (Chen et al. 2006; Shao, Lin 2002). In practical methods, the effect of implementing ES has been analyzed by measuring the time required to complete a sample task and by interviewing users. Companies that have not implemented ES in the past cannot apply these methods because they are applied after the implementation of ES. Thus, this approach is not useful in helping businesses evaluate whether adopting ES is profitable. This study proposes a method to analyze the effect of implementing ES, and it can be used by companies during the planning stages when they are deciding whether to implement ES. In this study, the effect of ES implementation is a reduction in working time.

The proposed method analyzes a change in the complexity of activities after an ES implementation. The change must be analyzed not for individual processes but for the entire set of processes (Hannula 2002), because a system is defined as a body unified by interconnecting processes and activities in terms of system theory (Agrell, Wikner 1996; Ducq et al. 2012). In this study, a process map (Figure 1) is used to help in the effect analysis to show the information flow before and after ES implementation based on the processes and activities in the workflow. The method is intended to be used by companies that have not previously implemented a similar ES because they have difficulty analyzing its effect. Especially, the usefulness of the method could be high for construction companies, because they have less experience with ES implementation than do manufacturing companies. This is because

*Corresponding author. E-mail: news3749@gmail.com 


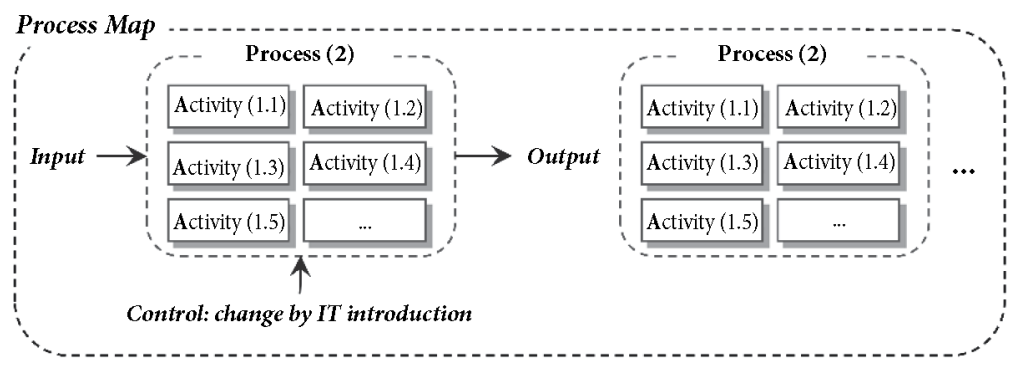

Figure 1. Composition of the process map

construction companies form separate organizational cultures at their headquarters and on construction sites, which are organized according to unique units and temporary projects (Lu, Wong 2007; Riley, Clare-Brown 2001).

This paper consists of three components. First, the necessity of the study is explained by reviewing the literature on ES implementation and its effect. Second, the proposed method of analyzing the effect based on the complexity of activities is explained. Third, the method is applied to a construction company that was considering implementing ES in the past and is doing so in the present. The results were evaluated by IT consultants who have been involved in the complete process of ES implementation.

\section{Literature review}

Most previous studies that analyzed the factors of ES system implementation success (Ahmad, Pinedo Cuenca 2013; Chou, Chang 2008; Ha, Ahn 2014; Hsu et al. 2015; Li et al. 2017; Nagpal et al. 2017; Nwankpa 2015; Ram et al. 2013; Ruivo et al. 2014; Soja 2009; Zhu et al. 2010) and the causality between ES implementation and its effect (Anderson et al. 2011; Badescu, Garcés-Ayerbe 2009; Galy, Sauceda 2014; Holsapple et al. 2017; Hu, Quan 2005; Livermore, Rippa 2011; Lu, Jinghua 2012; Nicolaou, Bhattacharya 2006; Ranjan et al. 2017; Swierczek, Shrestha 2003; Uwizeyemungu, Raymond 2012) proposed quantitative methods to analyze the effect of an ES after its implementation (Chang et al. 2011; Chen et al. 2006; Holsapple, Sena 2001; Lemonakis et al. 2018; Parthasarathy, Sharma 2016; Shao, Lin 2002; Usmanij et al. 2013; Uwizeyemungu, Raymond 2009; Wei 2008) and analyzed the possibility for success of ES (Chang et al. 2012; Hadidi et al. 2017; Hakim, A., Hakim, H. 2010; Ibrahim et al. 2018; Lee, C., Lee, C. 2017; Parhizkar, Comuzzi 2017; Parthasarathy, Sharma 2017; Subramanian, Peslak 2010; Sun et al. 2015). In contrast, the present study proposes a method to analyze the effect of ES implementation. The purpose of the method is to help companies decide whether to implement ES. The proposed method can be applied in the planning stages, so it is distinct from the methods used in previous studies.

Previously, critical success factors (CSFs) of ES implementation were proposed and analyzed (Table 1). For an analysis of the relation between factors, Chou and Chang (2008), Nagpal et al. (2017) and Zhu et al. (2010) derived
Table 1. Previous studies related to CSFs

\begin{tabular}{|l|l|}
\hline \multicolumn{1}{|c|}{ Authors } & \multicolumn{1}{c|}{ Main contents } \\
\hline $\begin{array}{l}\text { Nagpal } \text { et al. } \text { (2017), Chou and } \\
\text { Chang (2008), Ruivo } \text { et al. (2014), } \\
\text { Zhu } \text { et al. (2010) }\end{array}$ & $\begin{array}{l}\text { Analysis } \\
\text { interdependence and } \\
\text { relation between CSFs }\end{array}$ \\
\hline $\begin{array}{l}\text { Ahmad and Pinedo Cuenca (2013), } \\
\text { Ha and Ahn (2014), Hsu } \text { et al. } \\
\text { (2015), Li } \text { et al. } \text { (2017), Nwankpa }\end{array}$ & $\begin{array}{l}\text { An impact analysis of } \\
\text { the implementation } \\
\text { output of an ES after } \\
\text { (2015), Ram } \text { et al. } \text { (2013), Soja }\end{array}$ \\
determination of CSFs \\
\hline
\end{tabular}

impact factors from the benefits of ERP implementation and CSFs, and they analyzed interrelation and interdependence. Although one previous study did not analyze the relation between selected factors, Ruivo et al. (2014) selected factors that had an impact on ERP use and value, and they analyzed the causality between them. Then, the previous study analyzed whether ERP use impacts ERP value.

Previous studies related to the impact of CSFs are divided into management and system perspectives. For a management perspective, based on the determined CSFs, Ha and Ahn (2014) analyzed the impact on business process performance; Li et al. (2017) analyzed the impact on strategic alignment, risk management, resource management; and Ram et al. (2013) analyzed the relation with organization performance. Soja (2009) analyzed the greatest impact on the success of ES implementation. Meanwhile, for a system perspective, Hsu et al. (2015) analyzed the impact of differences in system, service, and information on ERP success. Nwankpa (2015) analyzed the impact of technical resources, organizational fit, and the extent of ERP implementation on ERP use and its benefits. Meanwhile, Ahmad and Pinedo Cuenca (2013) analyzed the impact of CSFs on organizational and operational performance in small and medium-sized companies in terms of both management and system perspectives.

These previous studies differ from this study in that this study offers a quantitative analysis of the effect of ES implementation, because previous studies aimed to derive the success factors that impact ES implementation.

In the previous studies, the causality between the ES and an implementation effect was analyzed differently according to the field and time of analysis (Table 2). The previous studies are divided into financial performance and 
Table 2. Previous studies related to causality analysis

\begin{tabular}{|l|l|}
\hline \multicolumn{1}{|c|}{ Authors } & Purpose of analysis \\
\hline $\begin{array}{l}\text { Anderson } \text { et al. (2011), Galy and } \\
\text { Sauceda (2014), Nicolaou and } \\
\text { Bhattacharya (2006), Ranjan } \text { et al. } \\
\text { (2017), Swierczek and Shrestha (2003) }\end{array}$ & $\begin{array}{l}\text { Causality } \\
\text { with financial } \\
\text { performance }\end{array}$ \\
\hline $\begin{array}{l}\text { Badescu and Garcés-Ayerbe (2009), } \\
\text { Holsapple et al. (2017), Hu and Quan } \\
\text { (2005), Uwizeyemungu and Raymond } \\
\text { (2012) }\end{array}$ & $\begin{array}{l}\text { Causality with } \\
\text { non-financial } \\
\text { performance }\end{array}$ \\
\hline $\begin{array}{l}\text { Livermore and Rippa (2011), Lu and } \\
\text { Jinghua (2012) }\end{array}$ & $\begin{array}{l}\text { Impact of } \\
\text { moderating factors }\end{array}$ \\
\hline
\end{tabular}

non-financial performance. For causality with financial performance, Anderson et al. (2011), Nicolaou and Bhattacharya (2006) and Galy and Sauceda (2014) analyzed the impact of ERP implementation on financial performance and the causality between them. Swierczek and Shrestha (2003) analyzed how investment in ES reduced cost and risk, as well as improved customer service, stabilized the customer base, and increased market share; ES investment was associated with an increase in net profit and asset increases, although the effect was difficult to quantify. For causality with non-financial performance, Badescu and Garcés-Ayerbe (2009) and $\mathrm{Hu}$ and Quan (2005) analyzed a relation between ES investment and productivity improvement. Holsapple et al. (2017) and Uwizeyemungu and Raymond (2012) analyzed the effect of ERP implementation in terms of business support processes. Ranjan et al. (2017) assessed the impact of new technology, such as cloud computing and social network computing, on ERP use considering non-financial (employee, process, customer) and financial performances. Although the effect was not analyzed according to ES implementation, Livermore and Rippa (2011) and Lu and Jinghua (2012) analyzed the impact of moderating factors, such as national culture and industry growth, on ERP implementation.

The cause-and-effect relationship of introducing ES was not consistent, so identifying consistent criteria to decide whether to implement ES is difficult.

The methods used in previous studies to analyze effect could be applied only after the implementation of ES (Table 3). These previous studies (Table 3) have higher relevance to this study than the previous studies related to CSFs (Table 1 ) and causality analysis (Table 2 ).

Table 3. Previous studies related to impact analyses of implementation

\begin{tabular}{|l|l|}
\hline \multicolumn{1}{|c|}{ Authors } & Purpose of analysis \\
\hline $\begin{array}{l}\text { Chang et al. (2011), Chen et al. (2006), } \\
\text { Parthasarathy and Sharma (2016), } \\
\text { Shao and Lin (2002) }\end{array}$ & Efficiency analysis \\
\hline $\begin{array}{l}\text { Holsapple and Sena (2001), Lemonakis } \\
\text { et al. (2018), Uwizeyemungu and } \\
\text { Raymond (2009), Wei (2008) }\end{array}$ & Effect analysis \\
\hline Usmanij et al. (2013) & Satisfaction analysis \\
\hline
\end{tabular}

For an efficiency evaluation of the ES, Chang et al. (2011) determined a key performance index (KPI) for the evaluation of an ERP system and proposed a method of efficiency evaluation based on the balanced scorecard (BSC) in management and support stage of the system. BSC is a performance management method using finance, customers, internal business processes, learning, and growth for the organizational vision and strategy. To maximize the efficiency of ES-related resource allocation, the method proposed by Chen et al. (2006) used the data envelopment analysis (DEA). The DEA is used when a relative efficiency of analysis target is evaluated by comparing with the input and output. Parthasarathy and Sharma (2016) analyzed the efficiency of an ERP package and the relation between the efficiency and level of customization. Shao and Lin (2002) proposed a model composed of DEA and the Tobit model and applied the combination to the production process. The DEA was used to measure technical efficiency, while the Tobit model was used to identify a possible causal relationship between the dependent and independent variables; the model was used to determine the existence of a causal relationship between ES investment and efficiency.

For the effect analysis, Holsapple and Sena (2001) analyzed managers' perceptions and the importance of the benefits and obstacle factors about decision-support benefits according to the implementation of an enterprise system. Lemonakis et al. (2018) analyzed a potential change in administrative accounting and internal control based on the effect of ERP use. Uwizeyemungu and Raymond (2009) analyzed the impact of ERP on organizational performance using a combination method with the process and scorecard model. Wei (2008) proposed a comprehensive framework for evaluating ERP performance by weighted project management, system, vendor, and impact. Furthermore, Usmanij et al. (2013) analyzed the relation between users' satisfaction and human-centered ERP implementation such as process, syntactic, semantic, social, and pragmatic.

However, much time and effort are necessary to analyze the effect of ES implementation; this effort complicates the measurement of the effect on workflow before and after ES implementation. Furthermore, because these previous studies can analyze the effect of ES introduced after the implementation, previous studies and this study differ.

Lastly, previous studies analyzed the possibility of success or proposed a method to improve the possibility of success (Table 4 ). To analyze the possibility of success, Chang et al. (2012) selected factors that impact ERP implementation, analyzed the grade of output using weighting, and predicted the possibility of success. Parhizkar and Comuzzi (2017) identified that a modification development after ERP implementation leads to a decrease in ERP system and data quality, having a negative impact on organizational performance. Subramanian and Peslak (2010) analyzed users' perceptions of ERP success. The users perceived that the effect of ERP is negative during the transition and maintenance stages among all ERP stages, such as 
Table 4. Previous studies related to the possibility of success

\begin{tabular}{|l|l|}
\hline \multicolumn{1}{|c|}{ Authors } & Purpose of analysis \\
\hline $\begin{array}{l}\text { Chang } \text { et al. (2012), Parhizkar and } \\
\text { Comuzzi (2017), Subramanian and } \\
\text { Peslak (2010), Sun } \text { et al. (2015) }\end{array}$ & $\begin{array}{l}\text { Analysis of the } \\
\text { possibility of } \\
\text { success }\end{array}$ \\
\hline $\begin{array}{l}\text { Hadidi } \text { et al. (2017), Hakim, A. and } \\
\text { Hakim, H. (2010), Ibrahim } \text { et al. } \\
\text { (2018), Lee, C. and Lee, C. (2017), } \\
\text { Parthasarathy and Daneva (2016), } \\
\text { Parthasarathy and Sharma (2017), } \\
\text { Sun et al. (2015) }\end{array}$ & $\begin{array}{l}\text { Method to improve } \\
\text { the possibility of } \\
\text { success }\end{array}$ \\
\hline
\end{tabular}

the preparation and training, transition, performance and usefulness, and maintenance phases.

To improve the possibility of success, Hadidi et al. (2017) introduced a decision-making method that determines the priorities of ERP modules to improve suitability to construction companies. Hakim, A. and Hakim, $\mathrm{H}$. (2010) proposed a method for selecting a suitable ERP system that can reflect the purpose of the introduction, as well as the strategies of the company, effect of the introduction, risk factors, technical feasibility, and internal requirements. Ibrahim et al. (2018) and Parthasarathy and Daneva (2016) analyzed a priority of collected requirements and proposed a decision model of a level and method of customization. In addition, for customization, Parthasarathy and Sharma (2017) analyzed the effect of ERP customization on software quality. Lee, C. and Lee, C. (2017) proposed a method to improve the effect of implementing an enterprise system by improving suitability. Sun et al. (2015) derived KPIs based on previous studies, then analyzed weighting, and proposed an application method for an organizational readiness assessment, ERP selection, ERP implementation, ERP final preparation, and ERP live run stages. If the performance is lower than expected, remedial action is also proposed.

In this study, the proposed method that analyzes the quantity effect before ES implementation is similar to the method of these previous studies that analyze the possibility of success. However, the method of the previous studies is difficult to apply before ES implementation and requires much time and effort. Furthermore, the other cases should be similar to the past case, when the success possibility was predicted using the method of previous studies for other cases.

The previous studies about the effect of implementing ES: 1) only involved analysis after ES implementation and 2) required significant time and money. The present study proposes a method that can be applied in the planning stages to analyze the effect of changes before ES is implemented. The proposed method is based on the complexity of the activities and processes shown on the process map. The required time and cost are less than for the practical method, because actual work time is not measured and no interviews or surveys are conducted. The research model of this study is explained in the following three sections.

\section{The proposed method for reducing working time}

A process consists of activities that are performed by work units, as well as systems to support the activities, approval and decision, and other organizations and processes related to the activities (Figure 2). If related processes or organizations do not complete tasks on time, subsequent tasks are also delayed. Thus, work complexity is effected by related processes and organizations. In this study, the complexity of activities considered the number of related processes and organizations.

Analyses of the effect by comparing processes one-toone before ES implementation (as-is process) to processes after ES implementation (to-be process) generally achieved high accuracy. However, one-to-one comparison methods require much time and cost. In addition, an activity included in the as-is processes may not have a corresponding activity in the to-be process, and vice versa. For example (Figure 2), the as-is processes for "countermeasure for progress control and process recovery" are divided into to-be processes for "construction plan review" and "scheduling management". However, activities that were included in asis processes may not be the same as activities included in to-be processes. The "establishment/discussion of scheduling plan" activities in the as-is processes are changed to 1) request for construction plan, 2) review of the construction plan, and 3) registration of the construction plans in the to-be processes. The "request construction plan" step of the to-be process is not an activity drawn from the as-is processes as the "establishment/discussion of scheduling plan"; rather, it is an activity drawn from the "establishment and management of accomplishment plans", which are other processes.

This study proposes a method to analyze the effect that considers a process map, not one-to-one comparison. The method consists of five steps (Figure 3). First, define and analyze the level of digitalized and automated activities by the ES implementation. Second, analyze work complexity based on the numbers of other processes and organizations related to activities. Third, analyze work complexity based on the numbers of processes and organizations related to processes. Fourth, integrate the level of digitalized and automated activities and the complexity of activities and processes. Finally, analyze employees' workload using implemented IT in the total work process.

\subsection{Definition and analysis of automated and digitalized activities}

In this study, the activities affected by ES implementation were divided into 'digitalized' and 'automated' (Table 5). Digitalized activities are partially performed by ES in place of manual method, and they are then passed on to linked activities to be completed by manual method. Automated activities are completed by ES and not carried over to other linked activities. 


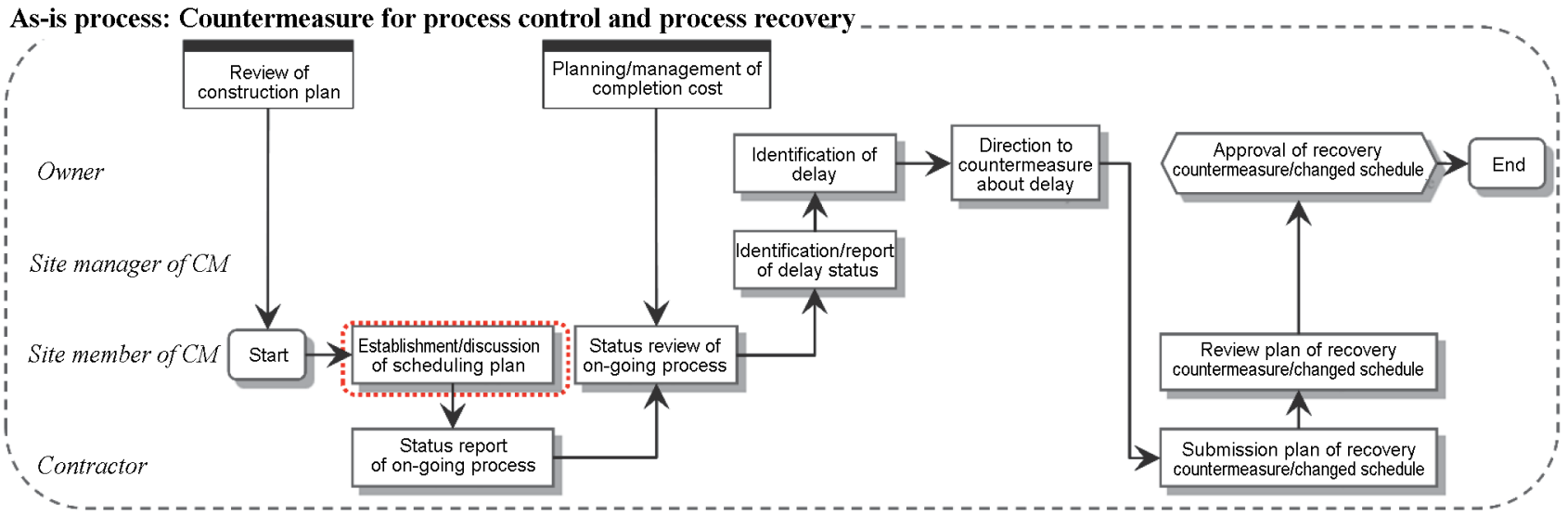

To-be process: Construction plan review

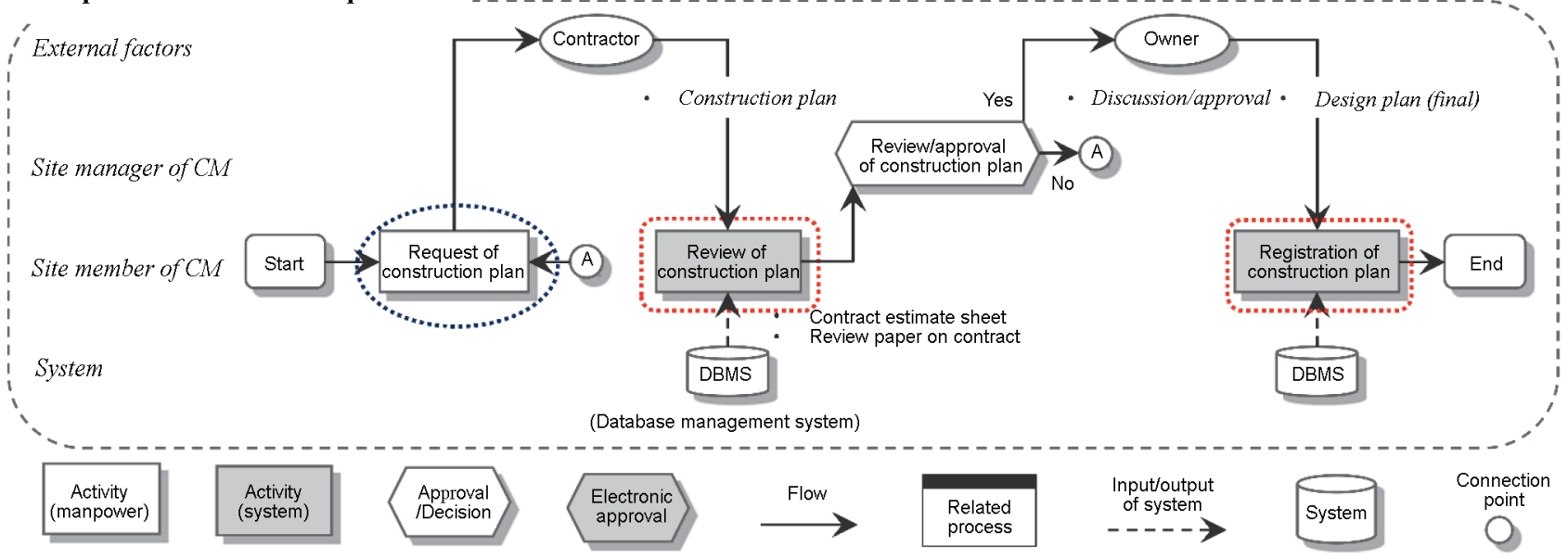

Figure 2. Example of a process map and a change from an as-is process to a to-be process

Table 5. Definition of digitalized and automated activities

\begin{tabular}{|cl|}
\hline Digitalized & \multicolumn{1}{c|}{ Automated } \\
\hline - The ES performs the activity, & - The ES performs the \\
but does not complete it. & activity completely on \\
- Digitalized activities are carried & its own. \\
over to other linked activities. & - Automated activities \\
- Linked activities are performed & do not involve manual \\
by manual method. & method. \\
\hline
\end{tabular}

Compared to activities that were performed by manual method previously, the effect on activities automated by ES implementation can be considered $100 \%$. However, the effect on digitalized activities can vary from 1-99\%, depending on the level of digitalized activities; the effect is difficult to quantify. To analyze uncertain boundaries, this study applied fuzzy theory, which is used to convert ambiguous information into useful information (Ustundag, Cevikcan 2016; Yazdani-Chamzini 2014), and the criteria for ES implementation effects are defined for the classification of the levels of digitalization and automation (Table 6). The effect of ES implementation on each automated activity was defined as ' 1 ' for digitalized activities, where the weighted values were calculated by applying triangular fuzzy numbers based on the levels of digitalization. The triangular fuzzy numbers are expressed as three points; thus, they can be easily approached conceptually and can be easily analyzed mathematically (Abdul-Rahman et al. 2013; Xu, Feng 2015).

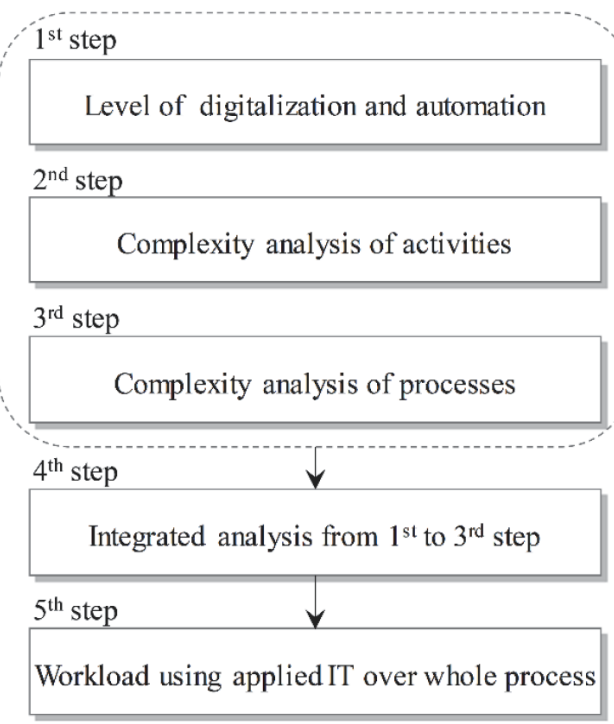

Figure 3. The proposed method for analyzing the effect of ES 
Table 6. Classification criteria of the effects of automated and digitalized activities

\begin{tabular}{|cll|}
\hline Division & Effect \\
\hline Automated & 1.00 & - Activities that do not require any additional manual method \\
\hline & $0.75 \quad \begin{array}{l}\text { - Additional activities completed using manual method that are unaffected by previous activities } \\
\text { - Each work is started and finished in their own one activity }\end{array}$ \\
\cline { 2 - 3 } Digitalized & $0.50 \quad \begin{array}{l}\text { - Additional activities completed using manual method that are affected by previous activities } \\
\text { - Activities are implemented based on activities in previous stages, such as "analysis and writing" }\end{array}$ \\
\cline { 2 - 3 } & $\begin{array}{l}0.25 \\
\text { - Additional activities completed using manual method require decision making, such as "approval } \\
\text { and decision" }\end{array}$ \\
- Activity performance is affected by the decisions of other organizations
\end{tabular}

\subsection{Weighting-based activity complexity}

Activity complexity is quantified by the number of processes and organizations related to the digitalized and automated activities after ES implementation. If activities are associated with other organizations related to work (e.g., owner, contractor, sub-contractor, other processes), the work complexity increases; if activities are not associated with other organizations, the work complexity is low. The activity complexity can be analyzed using Eqns (1)-(3):

$$
\begin{aligned}
& \alpha_{a s-i s}=c_{a s-i s} /\left(1+a_{a s-i s}\right), \alpha_{t o-b e}=c_{t o-b e} /\left(1+a_{t o-b e}\right) ; \\
& \beta_{a s-i s}=c_{a s-i s} /\left(1+b_{a s-i s}\right), \beta_{t o-b e}=c_{a s-i s} /\left(1+b_{t o-b e}\right) ; \\
& W_{a c t i v i t y}=(\alpha+\beta) / 2,
\end{aligned}
$$

where: $\alpha$ - weighting of other processes related to digitalized/automated activities; $\beta$ - weighting of other organizations related to digitalized/automated activities; $a$ number of other processes related to the relevant activity; $b$ - number of other organizations related to the relevant activity; $c$ - number of digitalized and automated activities; $W_{\text {activity }}$ - weighting reflecting activity complexity.

Equation (1) uses the method of weighting based on the number of other processes related to digitalized and automated activities. The number $\mathrm{c}$ of digitalized and automated activities in as-is or to-be processes is divided by $(1+a)$, where $\mathrm{a}$ is the number of processes related to the activities; ' 1 ' is added to account for cases that have no related process. Eqn (2) uses the method of weighting based on the number of other related organizations, and it is similar to Eqn (1). Eqn (3) averages the outputs of Eqn (1) and Eqn (2).

\subsection{Weighting based on process complexity}

A process complexity analysis is quantified by the number of activities, processes, and organizations related to all activities in the processes. Analyses assigned weights in proportion to process complexity for all activities that do not directly affect the digitalized and automated activities, but which may have indirect effects if they are delayed or discontinued by including them in the same or similar processes. Weighting based on process complexity can be analyzed using Eqns (4)-(6):

$$
\begin{aligned}
& W_{\text {process }}=1+(\delta+\varepsilon) / 2 \\
& \gamma_{a s-i s}=c_{a s-i s}-\left[(d \times e \times f)_{a s-i s} \times W_{\text {process_as-is }} \times c_{a s-i s}\right] \\
& \gamma_{t o-b e}=c_{t o-b e}-\left[(d \times e \times f)_{t o-b e} \times W_{\text {process_to-be }} \times c_{t o-b e}\right],(6)
\end{aligned}
$$

where: $\gamma$ - weighting that represents process complexity; $d$ - relative weighting of process Level $1 ; e$ - relative weighting of process Level $2 ; f$ - relative weighting of process Level 3; $W_{\text {process }}$ - weighting based on complexity of all activities included in the entire processes; $\delta$ - number of other processes related to all activities included in the entire processes; $\varepsilon$ - number of other organizations related to all activities included in the entire process.

Equation (4) assigns weightings based on the numbers of processes and organizations related to all activities included in the processes; it is divided by 2 to yield the average value of processes and organizations related to the activity; ' 1 ' is added to prevent the process-weighted values analyzed in Eqns (4) and (5) from becoming ' 0 '.

Equations (5) and (6) are used to analyze the complexity-weighted values based on the numbers of activities included in the individual processes in the entire hierarchized process. This is similar to the analytic hierarchy process (AHP), by which the relative importance for selection of optimal alternative based on hierarchy of effect factors. The analyzed importance of an upper level is given a weighted value to the lower level (Saaty 1990). For example, if hierarchies of processes are composed of Levels 1,2 , and 3 , then to analyze relative ratios, the number of all activities included in Level 1 processes is calculated (Figure 4). This is because it is affected by the total number of activities in the whole process, and the increase in work complexity is affected by the number of activities and processes and the number of organizations related to the corresponding process levels. Next, the relative ratios of complexity at Level 1 were therefore given to individual Level 2 processes, and the values were again given to Level 3 processes as weighted values. That is, if the relative complexity ratios of Level 1 and Level 2 are 15.90\% and $11.21 \%$, respectively, activities that constitute Level 3 will have the weighted value of $1.78 \%$, which is a relative weighting based on the complexity of the activities and processes. Relative weighting is the basic value used in the integrated analysis in the next section. 


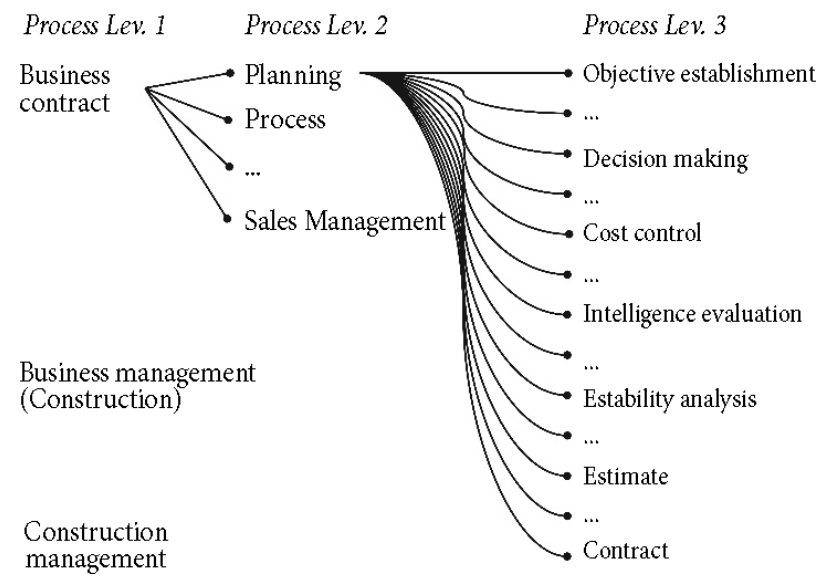

Figure 4. Example process hierarchy of the contract business

\subsection{Integrated analysis}

The level of digitalized and automated activities, the activity, and the process-based complexity can be aggregated (Eqn (7)). First, because the number of activities in as-is processes differs from that in to-be processes, this study multiplies $g$ by $j$, where $g$ is the number of activities that are digitalized and automated as a result of ES implementation and $j$ is the ratio of the numbers of activities in the two groups of processes (=to-be/as-is). Then, this study subtracts $g \times j$ from the number $h$ of activities in the as-is processes. Second, because the number $i$ of activities that are already digitalized and automated in as-is processes are not effects that can be obtained from ES implementation, then $i$ is added. Third, to analyze the effects of to-be processes based on as-is processes, this study divides the above value by $h$, the number of all activities in as-is processes. Because the value calculated in this way is the ratio of activities not digitalized or automated, even when ES has been implemented, the change ratio of the effect of ES implementation can be analyzed by subtracting/deducting the calculated value from 1 .

$$
X=1-\{h-(g \times j)+i\} / h=\{(g \times j)-i\} / h,
$$

where: $x$ - effect ratio of productivity by the level of digitalization and automation; $g$ - the number of digitalized and automated activities of to-be processes; $h$ - number of all activities in to-be processes; $i$ - number of digitalized and automated activities of as-is processes; $j$ - the ratio of total numbers of activities in to-be and as-is processes (= to-be/as-is).

\subsection{Works analysis with applied ES}

In the previous four steps, methods were proposed for analyzing the weighted values based on activity complexity and process complexity to analyze the effects of ES implementation. However, the implemented ES is not applied to all work processes. The effect is analyzed based only on the work to which ES is applied to ensure an accurate analysis. Eqn (8) is a method for analyzing the share of the entirety of the work processes taken by the implemented ES. The number of activities that had already been digitalized and automated before ES was implemented ( $\left.z_{-} a s-i s\right)$ was multiplied by $k$, the ratio of the numbers of activities in the two groups of processes (=as-is/to-be). Then, the value is deducted from the number of digitalized and automated activities in to-be processes, reflecting activity and process complexity $\left(z \_t o-b e\right)$. The resultant value is divided by the sum of the total number of activities in to-be processes $\left(l_{-} t o-b e\right)$, and the number of digitalized and automated activities, including the final weighted value $\left(-g_{-} t o-b e+\right.$ $z \_a s-i s$ ), should be applied:

$$
\mathrm{M}=\left(z_{t o-b e}-z_{a s-i s} \times k\right) /\left(l_{t o-b e}-g_{t o-b e}+z_{t o-b e}\right),
$$

where: $z_{t o-b e}$ - number of digitalized/automated activities including the final weighted value in to-be processes; $z_{a s-i s}$ - number of digitalized/automated activities including the final weighted value in as-is processes; $k$ - the ratio of the total number of activities in as-is and to-be processes $(=a s-i s / t o-b e) ; l_{t o-b e}-$ total number of activities in to-be processes; $g_{t o-b e}$ - total number of digitalized/automated activities in to-be processes.

\section{The case study}

In this section, the effect of ES implementation is analyzed by applying the proposed method to a case. Then, the meaning of the analysis result is evaluated through an interview with ES consultants who have participated in planning, construction, and operation of ES.

\subsection{The case overview and analysis method}

The method was applied to a construction company that had not had a similar ES implementation in the past. The construction company is located in Seoul, Korea, and it had $\sim$ USD 5 billion in contracts between August 2011 and September 2012. The business field of this company includes construction, plant, environment, and construction management $(\mathrm{CM})$. The number of employees is $\sim 2,000$. The ES that was considered for adoption was enterprise resource planning (ERP). The ERP was established in 2014, and operation began in 2015. The entire tobe process was classified into three steps (Levels 1,2, and 3) (Figure 4). The level of digitalization and automation and of activity and process complexity were analyzed at process Level 3, which is the time point at which the processes are completed. The analysis method used two steps:

1) The method is applied to Level 1 processes (Figure 4). This approach is used because Level 1 processes include contract business, construction business, and management business, which are the same in the asis and to-be processes.

2) The method is also applied to compare how the purpose of ES implementation affects its outcome. The purpose is determined through analyzing the process map for the case project, and the purpose is classified as follows: 
- Collection and requirement: application and acceptance; requirement and collection of data;

- Input: input and change; planning and standard establishment; analysis and action;

- Management: review, discussion and arrangement of input data; collaboration with other work;

- Report: representing and reporting the arranged data

- Consultation: approval request;

- Approval: decide, execute orders;

- Transmission and sharing: submit, notify, and share approval details.

To evaluate the analysis of the result, this study used an interview method to extract the opinions of IT consultants who participated in the planning, construction, and operation of implemented ES.

\subsection{Analysis of the effect of ES implementation}

The effect of ES implementation on various work processes (Level 1) was analyzed. The implementation had a large effect on management business (141.16\%) but small effects on other processes, such as business contract (5.44\%) and construction project management (4.96\%) (Table 7). The interview with IT consultants suggests that the effect of management business is high, because the main task is review and collaboration based on input data on construction sites, whereas construction project management was not strongly affected because construction projects are composed of separate sites, so uniform management by ERP is difficult.

The effect of the purpose of ES implementation was analyzed (Table 8 ). The proposed method indicated large effects on input (22.45\%) and management (16.79\%), but the effects on collection/requirement (3.09\%), report (1.03\%), consultation $(2.24 \%)$, approval $(0.01 \%)$, and transmission $(2.41 \%)$ were small. However, IT consultants evaluated all effects as low, except for management. Especially, they did not evaluate the effect on input as high, the reason being that users need time to adapt to a new system. After users become accustomed, the effect of input should increase.

The level of a total improved productivity is analyzed as $9.34 \%$ according to ERP implementation (Table 7 and Table 8). For converting the improved productivity to an economic effect, the average annual salary per head is

Table 7. Number of activities and effect depending on the process

\begin{tabular}{|c|c|c|c|c|c|c|c|}
\hline & & \multicolumn{2}{|c|}{ Business contract } & \multicolumn{2}{|c|}{$\begin{array}{c}\text { Construction project } \\
\text { management }\end{array}$} & \multicolumn{2}{|c|}{ CM business } \\
\hline & & $\begin{array}{l}\text { Manual } \\
\text { method }\end{array}$ & ERP & $\begin{array}{l}\text { Manual } \\
\text { method }\end{array}$ & ERP & $\begin{array}{l}\text { Manual } \\
\text { method }\end{array}$ & ERP \\
\hline \multirow{2}{*}{ The number of activities } & as-is & 126 & 7.53 & 570 & 1.28 & 65 & 2.17 \\
\hline & to-be & 51 & 40.01 & 151 & 129.79 & 49 & 80.93 \\
\hline \multicolumn{2}{|c|}{ Effect depending on the process } & \multicolumn{2}{|c|}{$5.44 \%$} & \multicolumn{2}{|c|}{$4.96 \%$} & \multicolumn{2}{|c|}{$141.96 \%$} \\
\hline \multicolumn{2}{|l|}{ Total effect } & & & \multicolumn{2}{|c|}{$9.34 \%$} & & \\
\hline
\end{tabular}

Table 8. Number of activities and effect depending on the purpose of ES implementation

\begin{tabular}{|c|c|c|c|c|}
\hline & & \multicolumn{2}{|c|}{ The number of activities } & \multirow{2}{*}{ Implementation effect } \\
\hline & & as-is & to-be & \\
\hline \multirow{2}{*}{ Collection and requirement } & Manual method & 124 & 47 & \multirow{2}{*}{$3.09 \%$} \\
\hline & ERP & 0.5 & 22.8 & \\
\hline \multirow{2}{*}{ Input } & Manual method & 227 & 106 & \multirow{2}{*}{$22.45 \%$} \\
\hline & ERP & 2.4 & 111.3 & \\
\hline \multirow{2}{*}{ Management } & Manual method & 192 & 44 & \multirow{2}{*}{$16.79 \%$} \\
\hline & ERP & 1.8 & 82 & \\
\hline \multirow{2}{*}{ Report } & Manual method & 31 & 13 & \multirow{2}{*}{$1.03 \%$} \\
\hline & ERP & 0 & 3.1 & \\
\hline \multirow{2}{*}{ Consultation } & Manual method & 23 & 0 & \multirow{2}{*}{$2.24 \%$} \\
\hline & ERP & 3.5 & 11.8 & \\
\hline \multirow{2}{*}{ Approval } & Manual method & 72 & 18 & \multirow{2}{*}{$0.01 \%$} \\
\hline & ERP & 2.2 & 5.9 & \\
\hline \multirow{2}{*}{ Transmission } & Manual method & 92 & 23 & \multirow{2}{*}{$2.41 \%$} \\
\hline & ERP & 0.6 & 15.7 & \\
\hline \multicolumn{4}{|c|}{ Total effect } & $9.34 \%$ \\
\hline
\end{tabular}


investigated as USD 50,134 in 2017 (exchange rate USD 1 = KRW 1117.0 as of June 27,2018 ) based on a business report of the case company. The expectable economic effect is analyzed as USD 9,365,031 annually, according to the ERP implementation and based on the average number of employees (about 2,000 persons), the average salary per head, and the level of improved productivity. If decisionmakers can identify the quantitative level of improved productivity and the economic effect before ES implementation, the information can contribute to decision-making regarding whether to invest.

\section{Conclusions}

Improved business efficiency is expected when a company implements IT (National IT Industry Promotion Agency 2008-2016). If the company that is considering implementing ES has implemented similar ES in the past, the effect of implementing ES can be analyzed approximately. However, construction companies that only recently implemented ES have insufficient data. The methods used by previous studies and the practical methods used to analyze the effect of implementing ES are applicable only after the implementation (Chen et al. 2006; Shao, Lin 2002), and they are expensive and time-consuming to complete.

This study proposed a method that can be used in the planning stages to analyze the effect (reduced working time) that results from the implementation of ES; the goal is to help companies decide whether to implement ES. The analysis criteria of the proposed method are the level of digitalized and automated activities and the complexity of the activities and processes. The proposed method was applied to a construction company that had constructed a process map for ES implementation and had completed the ES construction. First, the effect of ES implementation on processes was analyzed. The effect was high on management business but low on other processes. Next, the effect of the purpose of ES implementation was analyzed. The effect was high on the management of data but low on other process; especially, the effect on data input was low, because users were not accustomed to the implemented ERP. However, after users adapt to the ERP, the effect on input should increase.

The main contribution of this study is a method to analyze the effect in the planning stages prior to implementing ES. The proposed method will help construction companies decide whether to implement ES based on the quantitative expectation effect. Another contribution is the ability to identify processes in which working time will increase or decrease because construction companies can increase or decrease the investment based on the identified process and can modify the ES to improve the effect before implementation. Furthermore, functions of ES not appropriate for the company can be identified and modified before the ES is implemented. The proposed method requires less time and money than actual measurements, surveys, and interviews with ES users, because the analysis can be completed by one person in one day.
However, the process map for applying the proposed method is confidential data, because a significant cost is required to construct the process map. For this reason, this study did not collect the various process maps, and the proposed method did not apply to the various cases. This is the limitation of this study. In the future, the accuracy of the method will increase if more information is collected and the effect of ES implementation is quantified. Furthermore, after the implementation of an IT, a generating cost, such as maintenance cost during the life cycle, will be analyzed in future studies.

\section{References}

Abdul-Rahman, H.; Wang, C.; Lee, Y. L. 2013. Design and pilot run of fuzzy synthetic model (FSM) for risk evaluation in civil engineering, Journal of Civil Engineering and Management 19(2): 217-238.

https://doi.org/10.3846/13923730.2012.743926

Agrell, P. J.; Wikner, J. 1996. A coherent methodology for productivity analysis employing integrated partial efficiency, International Journal of Production Economics 46-47: 401411. https://doi.org/10.1016/S0925-5273(97)80001-9

Ahmad, M. M.; Pinedo Cuenca, R. 2013. Critical success factors for ERP implementation in SMEs, Robotics and ComputerIntegrated Manufacturing 29: 104-111.

https://doi.org/10.1016/j.rcim.2012.04.019

Anderson, M.; Banker, R. D.; Menon, N. M.; Romero, J. A. 2011. Implementing enterprise resource planning systems: organizational performance and the duration of the implementation, Information Technology and Management 12: 197-212. https://doi.org/10.1007/s10799-011-0102-9

Badescu, M.; Garcés-Ayerbe, C. 2009. The impact of information technologies on firm productivity: Empirical evidence from Spain, Technovation 29: 122-129.

https://doi.org/10.1016/j.technovation.2008.07.005

Chang, S.-I.; Yen, D. C.; Ng, C. S.-P.; Chang, I.-C.; Yu, S.-Y. 2011. An ERP system performance assessment model development based on the balanced scorecard approach, Information Systems Frontiers 13: 429-450. https://doi.org/10.1007/s10796-009-9225-5

Chang, T.-H.; Hsu, S.-C.; Wang, T.-C.; Wu, C.-Y. 2012. Measuring the success possibility of implementing ERP by utilizing the Incomplete Linguistic Preference Relations, Applied Soft Computing 12: 1582-1591. https://doi.org/10.1016/j.asoc.2011.12.008

Chen, Y.; Liang, L.; Yang, F.; Zhu, J. 2006. Evaluation of information technology investment: a data envelopment analysis approach, Computers \& Operations Research 33: 1368-1379. https://doi.org/10.1016/j.cor.2004.09.021

Chou, S.-W.; Chang, Y.-C. 2008. The implementation factors that influence the ERP (enterprise resource planning) benefits, Decision Support Systems 46: 149-157. https://doi.org/10.1016/j.dss.2008.06.003

Ducq, Y.; Chen, D.; Doumeingts, G. 2012. A contribution of system theory to sustainable enterprise interoperability science base, Computers in Industry 63: 844-857. https://doi.org/10.1016/j.compind.2012.08.005

Galy, E.; Sauceda, M. J. 2014. Post-implementation practices of ERP systems and their relationship to financial performance, Information \& Management 51: 310-319. https://doi.org/10.1016/j.im.2014.02.002 
Ha, Y. M.; Ahn, H. J. 2014. Factors affecting the performance of Enterprise Resource Planning (ERP) systems in the post-implementation stage, Behaviour \& Information Technology 33: 1065-1081. https://doi.org/10.1080/0144929X.2013.799229

Hadidi, L.; Assaf, S.; Alkhiami, A. 2017. A systematic approach for ERP implementation in the construction industry, Journal of Civil Engineering and Management 23(5): 594-603. https://doi.org/10.3846/13923730.2016.1215348

Hakim, A.; Hakim, H. 2010. A practical model on controlling the ERP implementation risks, Information Systems 35: 204-214. https://doi.org/10.1016/j.is.2009.06.002

Hannula, M. 2002. Total productivity measurement based on partial productivity ratios, International Journal of Production Economics 78: 57-67.

https://doi.org/10.1016/S0925-5273(00)00186-9

Holsapple, C.; Sena, M.; Wagner, W. 2017. The perceived success of ERP systems for decision support, Information Technology and Management. https://doi.org/10.1007/s10799-017-0285-9

Holsapple, C. W.; Sena, M. P. 2001. Beyond transactions: the decision support benefits of ERP systems, Journal of Decision Systems 10: 65-85. https://doi.org/10.3166/jds.10.65-85

Hsu, P.-F.; Yen, H. R.; Chung, J.-C. 2015. Assessing ERP postimplementation success at the individual level: Revisiting the role of service quality, Information \& Management 52: 925-942. https://doi.org/10.1016/j.im.2015.06.009

Hu, Q.; Quan, J. J. 2005. Evaluating the impact of IT investments on productivity: a causal analysis at industry level, International Journal of Information Management 25: 39-53. https://doi.org/10.1016/j.ijinfomgt.2004.10.006

Ibrahim, S. H.; Duraisamy, S.; Sridevi, U. K. 2018. Flexible and reliable ERP project customization framework to improve user satisfaction level, Cluster Computing. https://doi.org/10.1007/s10586-017-1664-Z

Lee, C.; Lee, C. 2017. Method to reduce the gap between construction and IT companies to improve suitability before selecting an enterprise system, Computers in Industry 85: 23-30. https://doi.org/10.1016/j.compind.2016.12.005

Lemonakis, C.; Sariannidis, N.; Garefalakis, A.; Adamou, A. 2018. Visualizing operational effects of ERP systems through graphical representations: current trends and perspectives, Annals of Operations Research.

https://doi.org/10.1007/s10479-018-2851-x

Li, H.-J.; Chang, S.-I.; Yen, D. C. 2017. Investigating CSFs for the life cycle of ERP system from the perspective of IT governance, Computer Standards \& Interfaces 50: 269-279.

https://doi.org/10.1016/j.csi.2016.10.013

Livermore, C. R.; Rippa, P. 2011. ERP implementation: A crosscultural perspective, Journal of Global Information Technology Management 14: 5-26.

https://doi.org/10.1080/1097198X.2011.10856541

Lu, M.; Wong, L.-C. 2007. Comparison of two simulation methodologies in modeling construction systems: Manufacturing-oriented PROMODEL vs. construction-oriented SDESA, Automation in Construction 16: 86-95.

https://doi.org/10.1016/j.autcon.2005.12.001

Lu, Z.; Jinghua, H. 2012. The moderating factors in the relationship between ERP investments and firm performance, Journal of Computer Information Systems 53: 75-84.

Mamoghli, S.; Goepp, V.; Botta-Genoulaz, V. 2015. An operational "Risk Factor Driven" approach for the mitigation and monitoring of the "Misalignment Risk" in enterprise resource planning projects, Computers in Industry 70: 1-12. https://doi.org/10.1016/j.compind.2015.01.010
Nagpal, S.; Kumar, A.; Khatri, S. K. 2017. Modeling interrelationships between CSF in ERP implementations: total ISM and MICMAC approach, International Journal of System Assurance Engineering and Management 8: 782-798.

https://doi.org/10.1007/s13198-017-0647-z

National IT Industry Promotion Agency. 2008-2016. Yearbook of information society statistics. Ministry of Public Administration and Security.

Ngai, E. W. T.; Law, C. C. H.; Wat, F. K. T. 2008. Examining the critical success factors in the adoption of enterprise resource planning, Computers in Industry 59: 548-564. https://doi.org/10.1016/j.compind.2007.12.001

Nicolaou, A. I.; Bhattacharya, S. 2006. Organizational performance effects of ERP systems usage: The impact of postimplementation changes, International Journal of Accounting Information Systems 7: 18-35.

https://doi.org/10.1016/j.accinf.2005.12.002

Nwankpa, J. K. 2015. ERP system usage and benefit: A model of antecedents and outcomes, Computers in Human Behavior 45: 335-344. https://doi.org/10.1016/j.chb.2014.12.019

Parhizkar, M.; Comuzzi, M. 2017. Impact analysis of ERP postimplementation modifications: Design, tool support and evaluation, Computers in Industry 84: 25-38. https://doi.org/10.1016/j.compind.2016.11.003

Parthasarathy, S.; Daneva, M. 2016. An approach to estimation of degree of customization for ERP projects using prioritized requirements, Journal of Systems and Software 117: 471-487. https://doi.org/10.1016/j.jss.2016.04.006

Parthasarathy, S.; Sharma, S. 2016. Efficiency analysis of ERP packages - A customization perspective, Computers in Industry 82: 19-27. https://doi.org/10.1016/j.compind.2016.05.004

Parthasarathy, S.; Sharma, S. 2017. Impact of customization over software quality in ERP projects: an empirical study, Software Quality Journal 25: 581-598. https://doi.org/10.1007/s11219-016-9314-x

Ram, J.; Corkindale, D.; Wu, M.-L. 2013. Implementation critical success factors (CSFs) for ERP: Do they contribute to implementation success and post-implementation performance?, International Journal of Production Economics 144: 157-174. https://doi.org/10.1016/j.ijpe.2013.01.032

Ranjan, S.; Jha, V. K.; Pal, P. 2017. Application of emerging technologies in ERP implementation in Indian manufacturing enterprises: an exploratory analysis of strategic benefits, The International Journal of Advanced Manufacturing Technology 88: 369-380. https://doi.org/10.1007/s00170-016-8770-6

Riley, M. J.; Clare-Brown, D. 2001. Comparison of cultures in construction and manufacturing industries, Journal of Management in Engineering 17: 149-158.

https://doi.org/10.1061/(ASCE)0742-597X(2001)17:3(149)

Ruivo, P.; Oliveira, T.; Neto, M. 2014. Examine ERP post-implementation stages of use and value: Empirical evidence from Portuguese SMEs, International Journal of Accounting Information Systems 15: 166-184.

https://doi.org/10.1016/j.accinf.2014.01.002

Saaty, T. L. 1990. How to make a decision: The analytic hierarchy process, European Journal of Operational Research 48: 9-26. https://doi.org/10.1016/0377-2217(90)90057-I

Shao, B. B. M.; Lin, W. T. 2002. Technical efficiency analysis of information technology investments: a two-stage empirical investigation, Information \& Management 39: 391-401. https://doi.org/10.1016/S0378-7206(01)00105-7

Soja, P. 2009. Enterprise system implementation issues: learning from field study in Poland, Enterprise Information Systems 3: 173-200. https://doi.org/10.1080/17517570802398216 
Subramanian, G. H.; Peslak, A. R. 2010. User perception differences in enterprise resource planning implementations, Journal of Computer Information Systems 50: 130-138.

Sun, H.; Ni, W.; Lam, R. 2015. A step-by-step performance assessment and improvement method for ERP implementation: Action case studies in Chinese companies, Computers in Industry 68: 40-52.

https://doi.org/10.1016/j.compind.2014.12.005

Swierczek, F. W.; Shrestha, P. K. 2003. Information technology and productivity: a comparison of Japanese and Asia-Pacific banks, The Journal of High Technology Management Research 14(2): 269-288.

https://doi.org/10.1016/S1047-8310(03)00025-7

Usmanij, P. A.; Khosla, R.; Chu, M.-T. 2013. Successful product or successful system? User satisfaction measurement of ERP software, Journal of Intelligent Manufacturing 24: 1131-1144. https://doi.org/10.1007/s10845-012-0645-6

Ustundag, A.; Cevikcan, E. 2016. Maximizing the value of residential projects using fuzzy rule based linear programming, Journal of Civil Engineering and Management 22(7): 853-861. https://doi.org/10.3846/13923730.2014.914102

Uwizeyemungu, S.; Raymond, L. 2009. Exploring an alternative method of evaluating the effects of ERP: a multiple case study, Journal of Information Technology 24: 251-268. https://doi.org/10.1057/jit.2008.20

Uwizeyemungu, S.; Raymond, L. 2012. Impact of an ERP system's capabilities upon the realisation of its business value: a resource-based perspective, Information Technology and Management 13: 69-90. https://doi.org/10.1007/s10799-012-0118-9

Wei, C.-C. 2008. Evaluating the performance of an ERP system based on the knowledge of ERP implementation objectives, The International Journal of Advanced Manufacturing Technology 39: 168-181. https://doi.org/10.1007/s00170-007-1189-3

$\mathrm{Xu}, \mathrm{J}$.; Feng, C. 2015. Two-stage based dynamic earth-rock transportation assignment problem under fuzzy random environment to earth-rock dam construction, Journal of Civil Engineering and Management 21(6): 775-797.

https://doi.org/10.3846/13923730.2014.893909

Yazdani-Chamzini, A. 2014. Proposing a new methodology based on fuzzy logic for tunnelling risk assessment, Journal of Civil Engineering and Management 20(1): 82-94. https://doi.org/10.3846/13923730.2013.843583

Zhu, Y.; Li, Y.; Wang, W.; Chen, J. 2010. What leads to postimplementation success of ERP? An empirical study of the Chinese retail industry, International Journal of Information Management 30: 265-276.

https://doi.org/10.1016/j.ijinfomgt.2009.09.007 